\title{
Surgical considerations in the treatment of skeletal hyperdivergence
}

\author{
Jean-Francois TULASNE, Eric SOLYOM
}

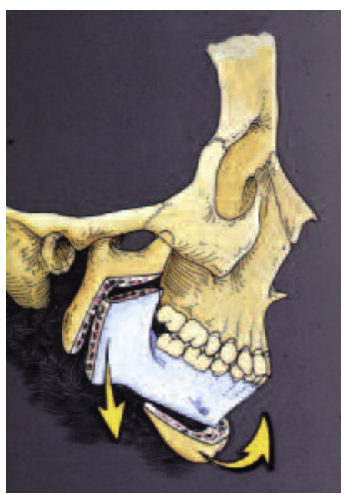

\section{ABSTRACT}

The surgical treatment of maxillo-mandibular malformations accompanying cases of hyperdivergence should aim at achieving good function for the patient by increasing space available for the tongue to move in and for proper respiration to take place and by reducing the tensions affecting muscles and ligaments either by dis-inserting them or by moving skeletal structures in the direction that muscles attached to them contract. An analysis of the literature shows that by respecting these principles surgeons can obtain good results in the majority of cases even in instances of extreme deficiency of the body of the mandible or where lengthening of the ascending rami is required. For these patients a cooperative effort of the surgeon and the orthodontist becomes even more than ever indispensable. In addition it will be necessary for the treatment team to follow these patients for an extended post-operative period.

\section{KEYWORDS}

\author{
Mandibular deficiency \\ Posterior rotation \\ Osteotomy for lengthening of mandible \\ Rotation of the occlusal plane \\ Genioplasty.
}


In orthodontics hyperdivergence is defined as an excessively oblique relationship of the mandibular and occlusal planes to the S-N line or the Frankfort plane. In cephalometric terms this anomaly can be readily discerned in the various clinical tables where the skeletal deviations caused by hyperdivergence are well highlighted by Delaire's architectural and structural analysis ${ }^{6,7}$.
Like their orthodontic colleagues oral surgeons tend to be reluctant to undertake treatment of hyperdivergent cases. Sometimes referred to as "high angle" cases, these disorders have an elevated rate of relapse and, more than any other disorder, require for successful outcomes well conducted surgical techniques and well executed orthodontic treatment for the attainment of satisfactory and stable results.

\section{CLINICAL TABLES DERIVED FROM THE DELAIRE ANALYSIS}

According to the Delaire craniofacial analysis, the line CF 7 that is an extension of the occlusal plane is normally tangent to the base of the occipital bone (fig. 1). But in cases of hyperdivergence, this high angle line penetrates into the skull. By tracing it and other lines, the examiner can determine if the hyperdivergence is due to :
- a posterior mandibular rotation caused by excess maxillary growth (fig. 2) or by downward tilting of the body of the mandible accompanied by an anterior tongue thrust (fig. 3),

- or to inadequate growth of the ascending rami (fig. 4 a).

\section{PROBLEMS IN TREATING HYPERDIVERGENCE}

Even though certain functional appliances, used at a very early stage, and, especially, new bone-inserted fixed anchorage devices have made it possible for practitioners to accomplish tooth and orthopedic movements hitherto impossible, such as intrusion of upper molars, the primary therapy for reducing hyperdivergence remains surgical whether the required correction is lengthening the ascending branches of the mandible, reducing maxillary height, or increasing space available for the tongue by enlarging and advancing the maxilla.
These objectives cannot always be readily achieved. While it has been shown that intrusion, or impaction, of the maxilla is an operation that routinely provides very stable results, retrospective studies have shown that attempts to increase posterior facial height by lengthening the vertical sectors of the mandible are, in the long term, likely to relapse $e^{13,14,15}$. This reason for this failure is the upward tension against the rami exerted by soft tissues, especially the pterygo-masseter bundle of the muscles of mastication, the hyoid muscles, and the very 

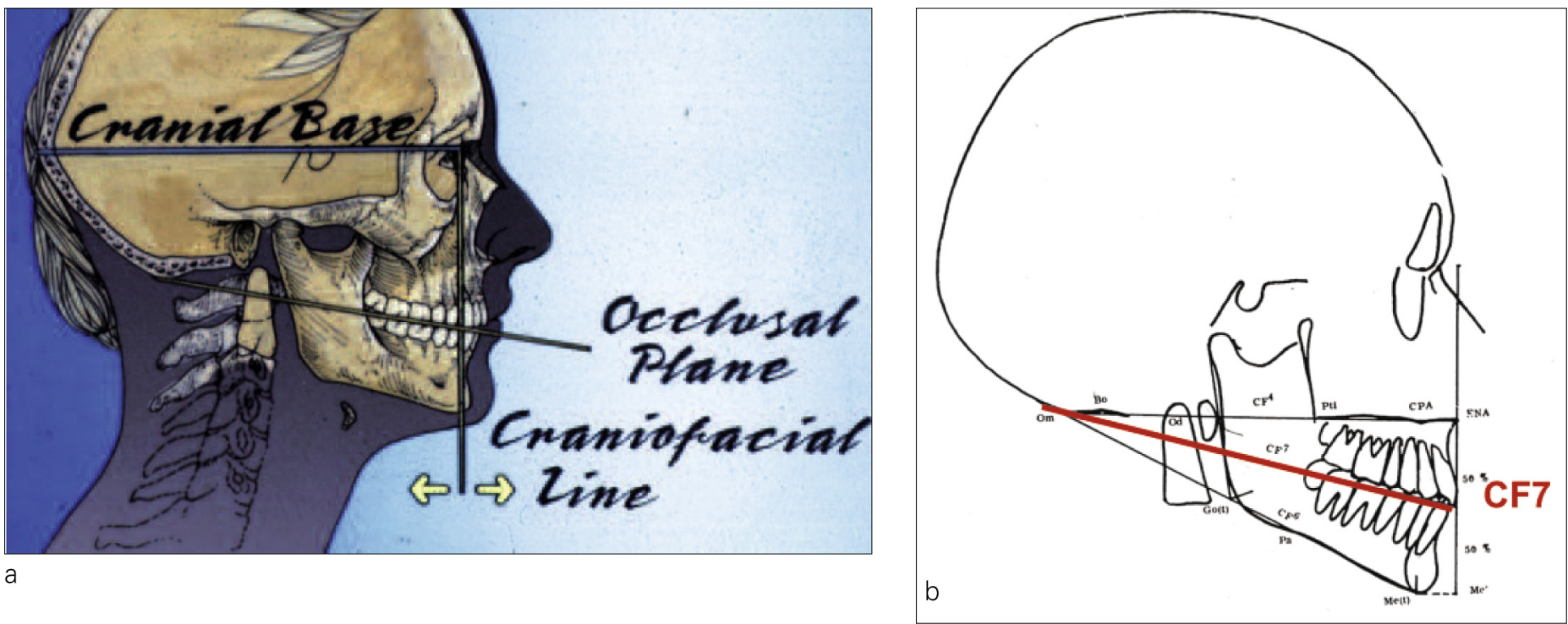

Figures 1 a and $b$

According to Delaire's architectural analysis, the line CF 7 or the cranio-occlusal line extended from the occlusal plane normally runs tangent to the base of the occipital bone or intrudes slightly into the cranium. But in cases of hyperdivergence it intrudes steeply into the cranium. (the design of figure $1 \mathrm{a}$ is taken from Merri Sheitlin).

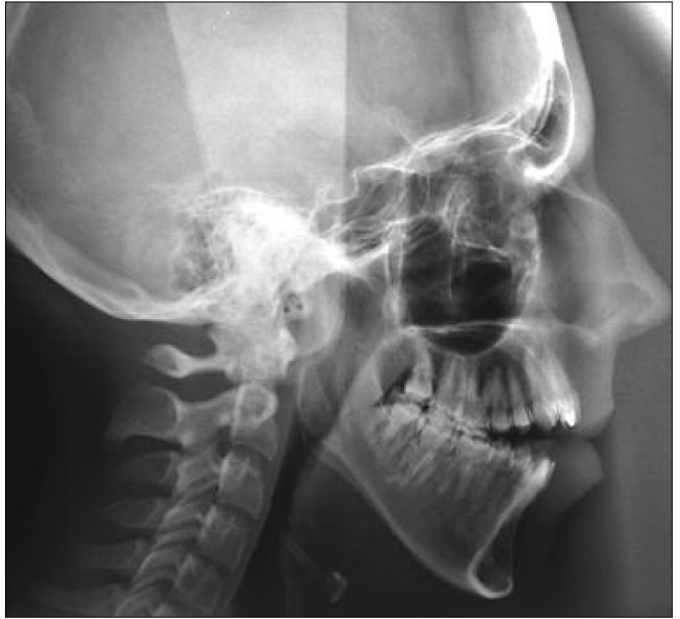

Figure 2

Hyperdivergence caused by excess vertical growth of the maxilla.

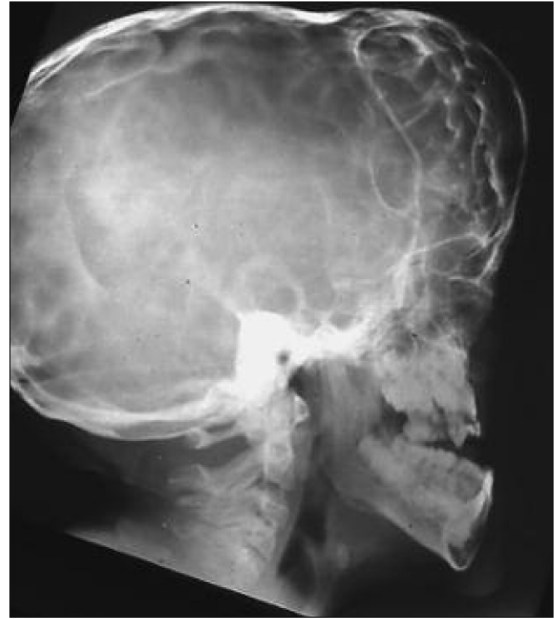

Figure 3

Hyperdivergence in a child afflicted with Crouzon disease, cranio-facio-stenosis, with maxillary atresia and tongue thrust causing a downward tilting of the body of the mandible.

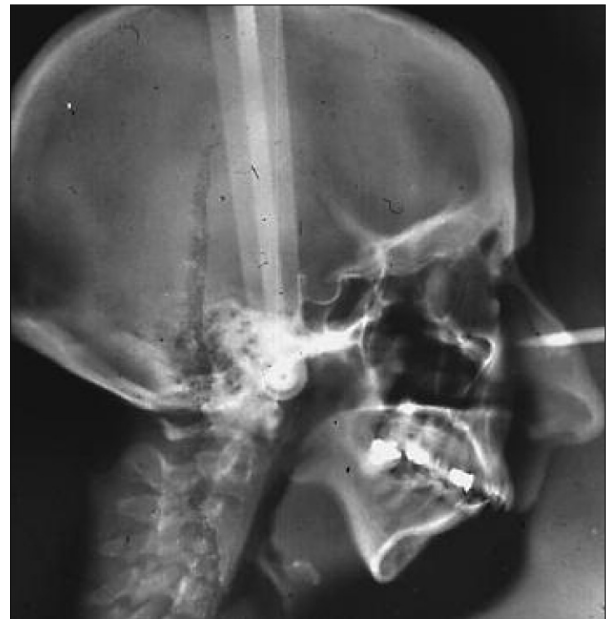

Figure 4 a

Hyperdivergence caused by shortness of the ascending branches of the mandible. An attack of rheumatoid poly-arthritis had caused destruction of heads of the condyles. The curvature of the inferior border of the mandible is characteristic of cases of tempero-mandibular ankyloses. 


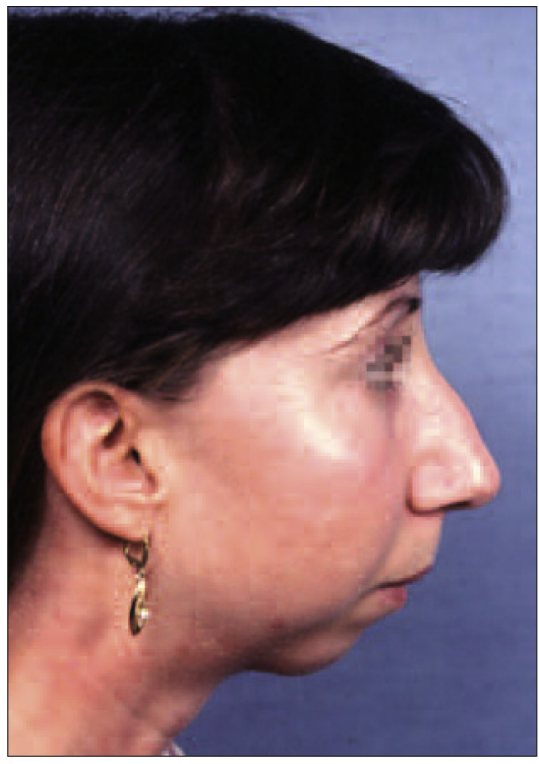

b

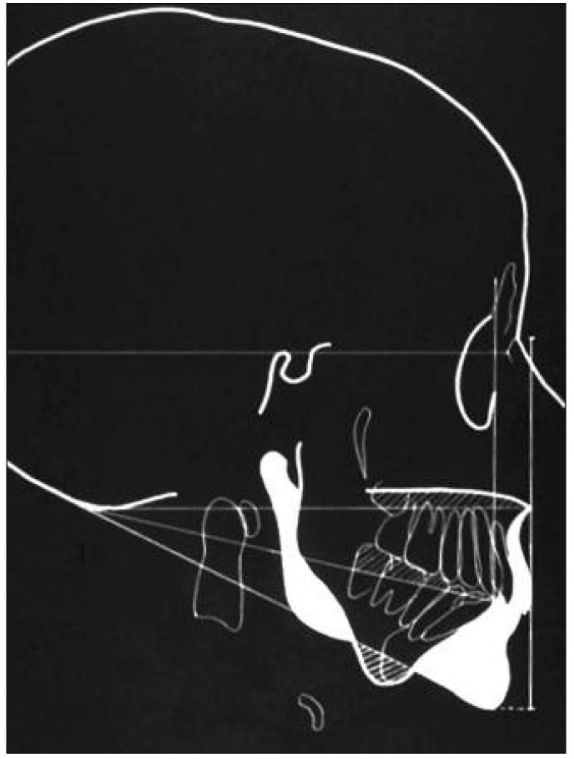

C

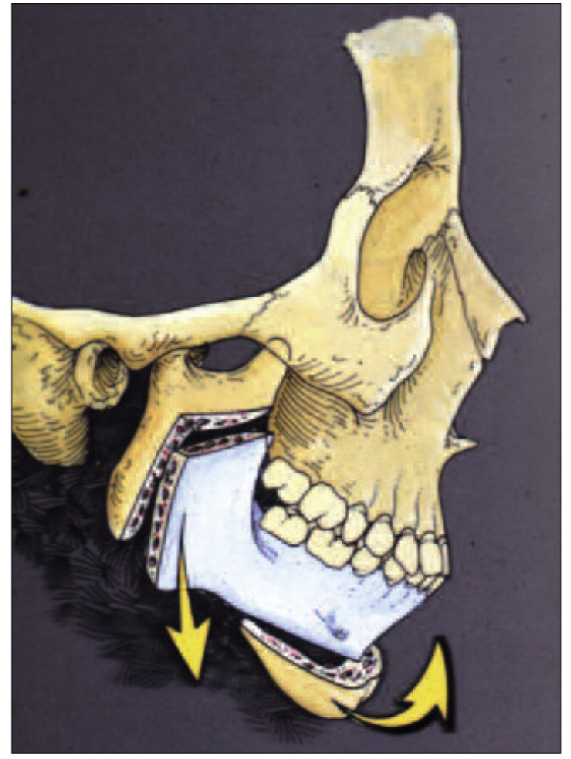

d

Figures $4 b$ to $d$

Delaire's architectural analysis gives a clear picture of the ideal positions of the maxilla and the mandible in relation to the cranium and to the spinal column (c). The illustration depicts surgery, L version osteotomies and a genioplasty, performed in 1981 on the patient shown in (a) with the surgical displacements depicted I (d). (Design by Merri Sheitlin).

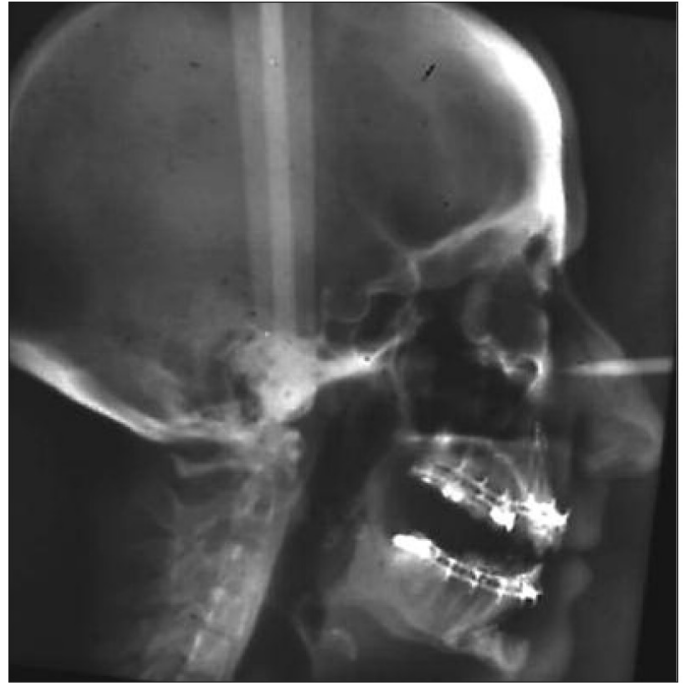

e

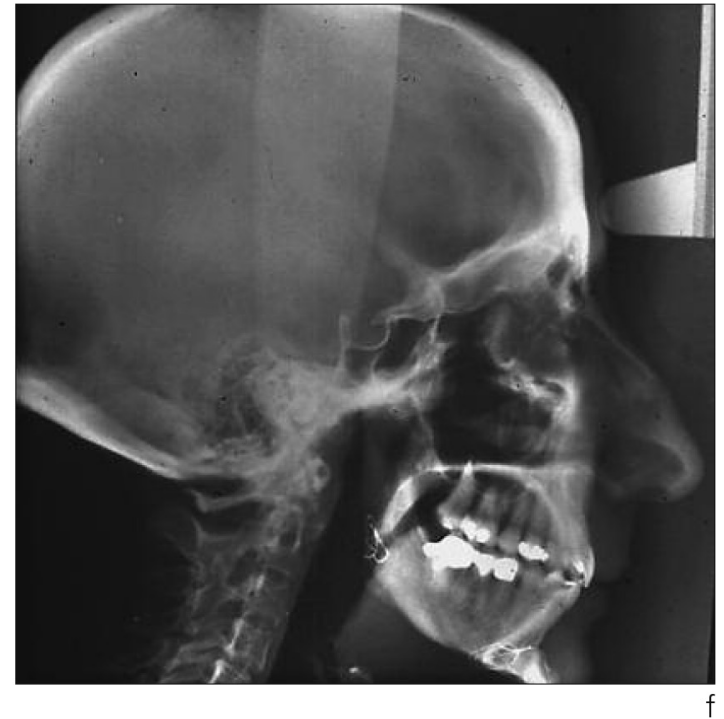

Figures 4 e and $f$ Cephalometric view after 2 months shows menton advanced $30 \mathrm{~mm}$ with a posterior block placed to correct the anterior open bite (e) and the second film ( $f$ ) shows the result 21 months after the operation. 
powerful spheno-mandibular ligament that is attached near the mandibular foramen.
That is why counter clockwise pressures on the mandible are usually inadvisable, unless it occurs

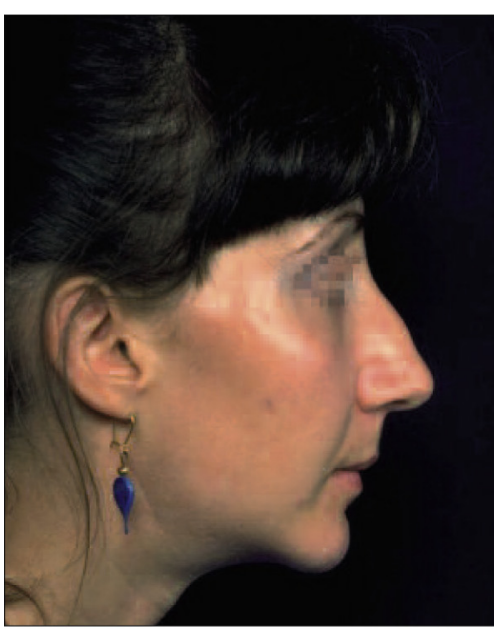

g
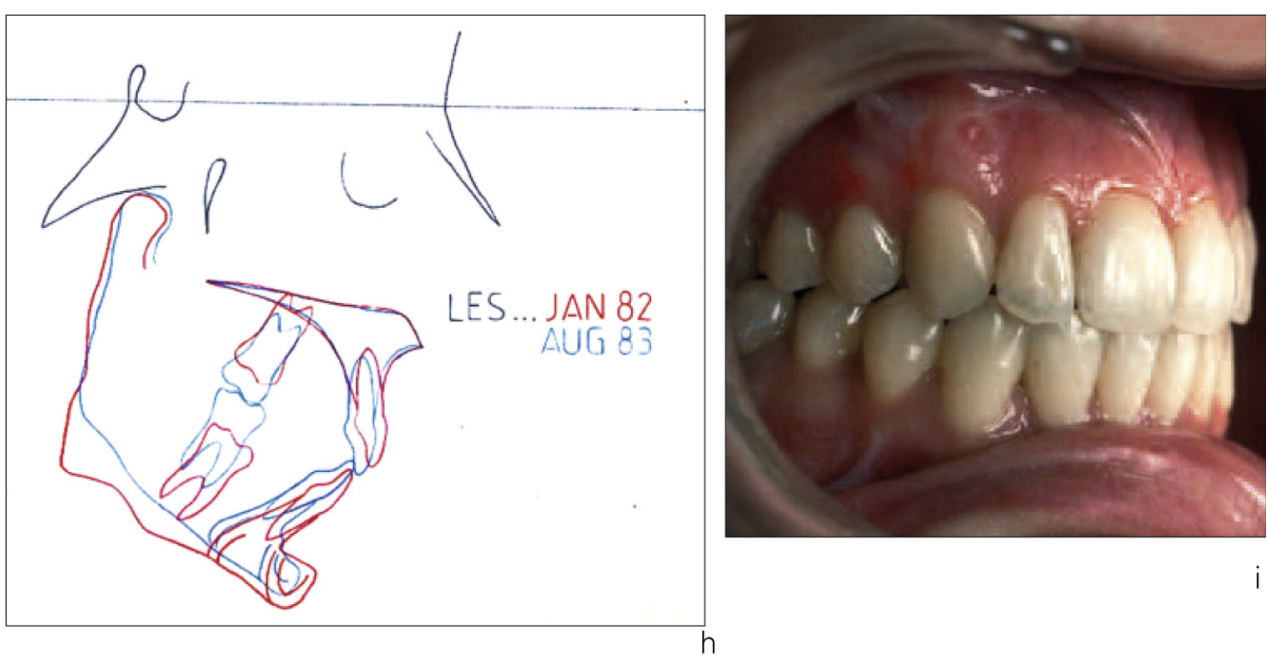

Figures $4 \mathrm{~g}$ to $i$

The clinical picture at the end of treatment (the orthodontist was J-C. Cholet). Superimposition of the cephalometric tracings at 2 months and 21 months post-operative (by G. Rozencweig) show the intrusion of the molars achieved in 18 months and a $2 \mathrm{~mm}$ relapse in the symphasis and of the teeth. (i).

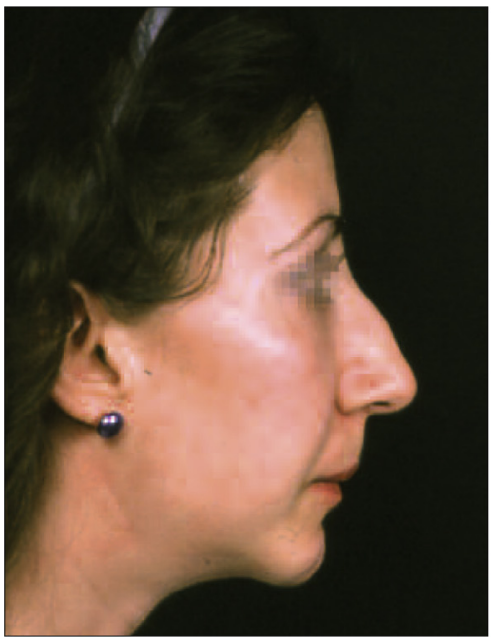

j

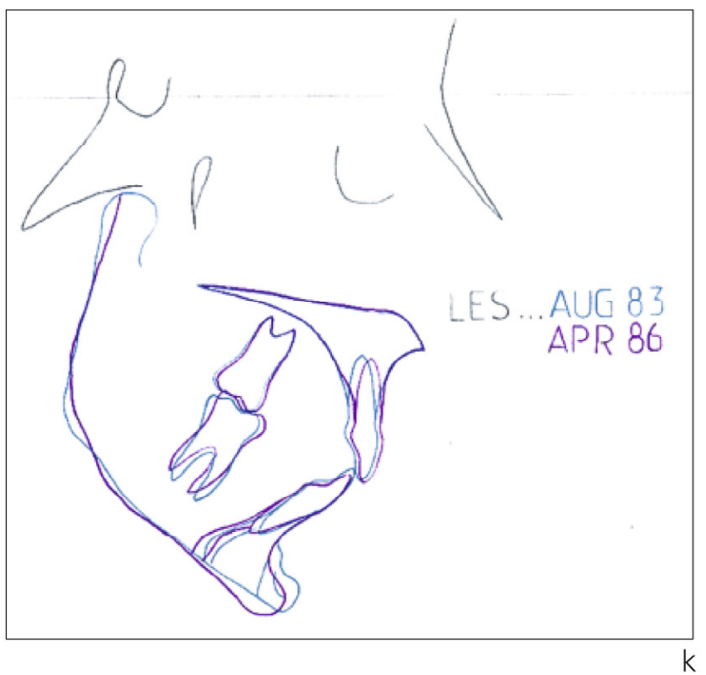

Figures 4 j to I

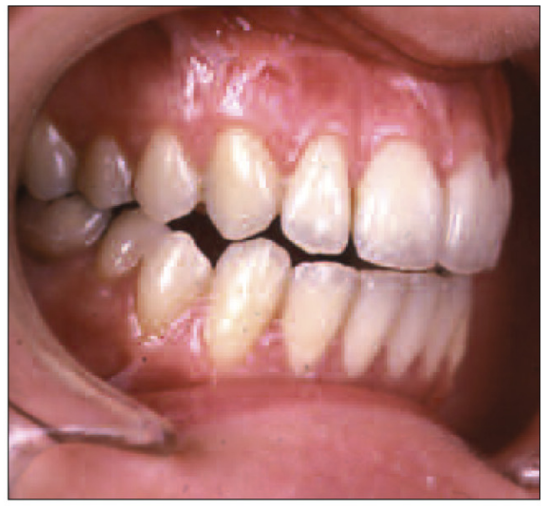

k

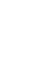


"spontaneously" as a result of surgical intrusion of the maxilla. This upward and forward auto-rotation of the mandible is stable because it flows in the direction in which the masticatory muscles relax, as do upward surgical displacements of the maxilla. The reverse, counter-clockwise lengthening of the ascending rami, whose action flows into contractions of the muscles of mastication, invites, as we have said, relapse. In other words, surgical closure of open bites should be stable and to insure this insofar as possible surgeons should always intrude the posterior sector of the maxilla as much as possible ${ }^{26}$.

However, the completely reasonable attempts by surgeons to carry out their procedures in ways that place repositioned structures in harmony with muscular forces do not always produce the best esthetic results and functional equilibrium. All surgical undertakings should make correction of abnormal structures their first priority and mandibular deficiency, for example, especially when it is aggravated, appears logically to require augmentation of the length of the cending branches by osteotomies and increasing the length of the body of the mandible by a genioplasty. This anterior rotation of the mandibular corpus with a lowering of the posterior segment of the occlusal plane projected the anterior

\section{SURGICAL TECHNIQUES (fig. 5)}

\section{- Le Fort 1 maxillotomy}

The tracing of a Le Fort 1 total maxillotomy shows no special characteristics. Even though the curve of

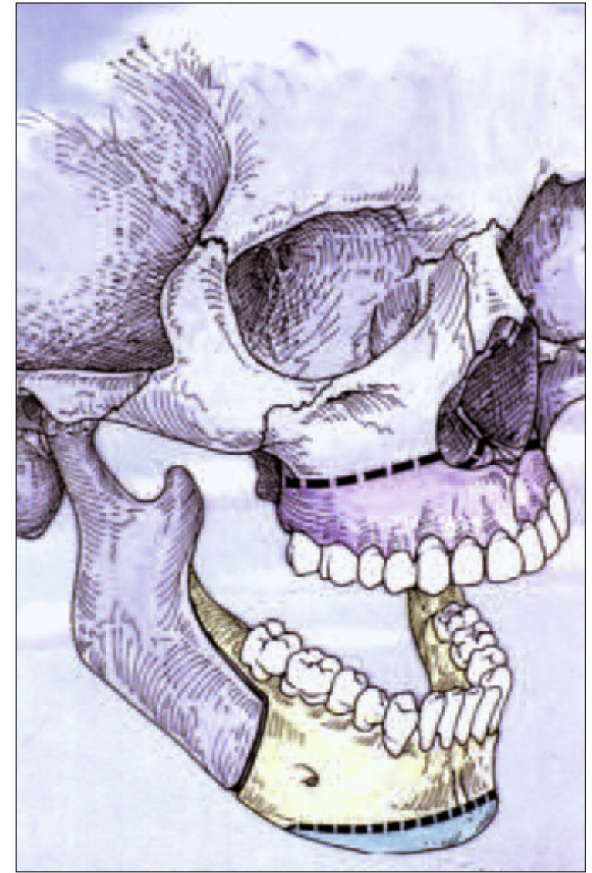

Figure 5

Depiction of the osteotomies most used in current orthognathic surgery: Le Fort 1, Obwegeser, genioplasty (illustration by Merri Sheitlin).

portion of the face forward, increased pharyngeal space as well as space available for the tongue, and corrected the hyperdivergence by attacking the root causes of the anomaly. In spite of the technical difficulties of the procedure and the potential risk of partial relapse this was the logical treatment and it provided functional improvements that were as important as the facial morphological benefits (fig. 4 b to I).

Spee is quite pronounced in the type of case pictured in Figure 5, surgeons will be able to divide the maxilla into three or four segments so as to level the arch and expand it if necessary. 
The surgeons determine the extent of displacement required from data derived from the clinical examination and from a cephalometric study in these parameters :

- anterior or posterior rotation according to the orientation of the maxillary occlusal plane

- advancement

- expansion, which, according to the form of the arch and the degree of movement involved, could be immediate with V-shaped arches, or performed later, progressively, with a palatesplitting expansion screw.

\section{- Mandibular osteotomies}

Two types of osteotomies can be performed on the mandible, the inverted $\mathbf{L}$ that Trauner described in $1957^{22}$, or the more frequently employed sagittal split of the ascending rami that Obwegeser described in the same article and that Dal Pont suggested in $1961^{5}$ should be extended forward to the posterior part of the mandibular corpus. To these procedures surgeons frequently add a genioplasty, whose repercussions on the labio-menton complex and on tongue activity are just as important as its positive esthetic effects ${ }^{8}$.

By progressively lengthening the vertical branches of the mandible by means of an internal or external distractor after they have been sectioned by an angular or a horizontal osteotomy surgeons can advance the body of the mandible and develop additional un-blocked bucco-pharyngeal space without using a bone graft but not without imposing some constraints on the patient.
- Prevention of relapse after mandibular advance

Soon after 1970 surgeons began to devise measures to prevent the high, well-documented incidence of relapse, including return of anterior rotation, after surgical treatment of short mandibles, a relapse whose noxious aspects increased in relation to the extent of the lengthening. They began to include in their protocols certain techniques or variations of procedure that would liberate the body of the mandible from the postoperative muscular and ligamentary tensions that might cause undesirable secondary displacement of mandibular segments preventing achievement of normal and stable end of treatment occlusion. They focused on a variety of operative aspects, the type of osteotomy, the cutaneous approach, dis-insertion of muscles and ligaments, over-correction of the malocclusion, and rigid inter-maxillary and osteosynthesis fixations. We shall discuss each in turn.

\section{Mandibular osteotomies}

The inverse L osteotomy has long been considered the most stable, especially when it is performed from an external, cutaneous approach or, better, a mixed external and internal approach, because with it surgeons can expose the entire ascending branch, easily cut the attachments of muscles and ligaments whose contraction would oppose the osseous extension, and assure a good placement of the condyle when the bone fragments are joined. And its principal attraction is that this surgical technique poses no direct risk to the inferior 
alveolar nerve. Unfortunately, it also has some serious drawbacks:

- using it surgeons cannot join the bone fragments in a way that is rigid enough to forestall bi-maxillary blockage

- when the mandible is advanced, the surgeon must fill the diastasis between the fragments with a bone graft

- when the operative approach is made at the mandibular angle a scar is left that, happily, is usually scarcely visible.

Because of these inconveniences and thanks to improvement in surgical techniques, the inverse L osteotomy and cutaneous approaches have now been virtually abandoned in favor of the sagittal split Obwegeser-Dal Pont procedure.

\section{Muscular dis-insertions}

The point in lengthening ascending branch operations at which surgeons dis-insert muscles is critical. It occurs at a time when the body of the mandible is literally "floating", when surgeons can create without forcing an opening of up to $15 \mathrm{~mm}$ between maxillary and molar teeth while the incisors are kept in contact. At this time the surgeon detaches the muscles and ligaments whose action opposes movement of the body of the mandible, the pterygo-masseter bundle, the spheno-mandibular ligament, and the supra-hyoid muscles.

- The at least partial dis-insertion of the sub-hyoid muscles is indispensible in all cases where advancement of menton is greater than $15 \%$ of the distance from menton to the hyoid bone according to Epker $^{9}$. Surgeons can easily accom- plish this in an intra-oral approach, usually during the genioplasty procedure that is often associated with a lengthening of the ascending branches, as Steinhauser proposed in $1973^{21}$.

- Surgeons dis-insert the pterygomasseter bundle during an Obwegeser-Dal Pont sagittal osteotomy procedure, a technique used for most mandibular corpus advancements because it permits operators to fixate segments with osteosynthesis devices sturdy enough to make osseous grafts unnecessary. By using a buccal approach surgeons gain direct access to the external surface of the posteroinferior border of the mandibular angle where they can readily cut the masseter attachment. They could then incise the periosteum to "open the periosteal sac" as Wolford $^{27}$, and, later, Ferri ${ }^{10}$, proposed. But these precautions are not alone sufficient to stabilize the re-connected mandible, because the very powerful internal ptyergoid muscle fibers and some ligaments are attached to the internal surface of the angle and surgeons can readily dis-insert them from an initial lingual approach, starting from the necks of the molars and the premolars. This technique of "mandibular liberation" seems to us simpler and just as effective as sectioning of cortical bone directly behind the last molar to liberate the mandible from muscular and ligamentary tensions as Ricard and Ferri $^{19}$ suggested, an attachment cutting process that dangerously requires bone scraping near Spix's Spine and the mandibular canal. 


\section{Over-correction}

Skeletal structures that surgeons move because they place undesirable tension on certain soft tissues, especially muscles and aponeuroses, obviously have a tendency to relapse after surgery. This is the case with lateral mandibular surfaces when the mandible remains under tension, primarily from short muscle fibers on the deviated side, after surgeons had recentered it. In such cases, overcorrection is frequently advisable to the extent that would later be correctable by orthodontic means. The same is true for lengthening procedures on the ascending rami to the extent that the posterior open bites thus created can readily be corrected by the use of vertical elastic bands. In all cases of hyperdivergence caused by mandibular insufficiency it is advisable for surgeons to over-correct, while maintaining a space between upper and lower molars as great as the anterior rotation of the mandible. Poulton and Ware ${ }^{14,15}$ proposed and carried out such an over-correction on two patients in 1971. And, in 1978, our mentor Delaire, on the basis of his architectural and structural analysis, encouraged us to operate on two patients, one of them a 9 year-old child, who had micro-mandibles, by creating a $10 \mathrm{~mm}$ gap between upper and lower first molars, which allowed us to elongate the ascending rami by $20 \mathrm{~mm}^{23,24}$.

\section{Osteosynthesis}

Any advancement of the mandible, no matter how minor, causes the heads of the condyles to move out of the glenoid fossa. In cases of where splints have been placed between upper and lower molar teeth and in the absence of an osteosynthesis that forces the condyles upward and backward, relapse is inevitable once the splints are removed. The over-correction in the splint between molars that Poulton and Ware, who attributed relapse exclusively to the force exerted by the supra-hyoid muscles, was designed to compensate for secondary displacement of the condyles. In a 1973 follow-up article, they stated that it was necessary for surgeons to accomplish osteosynthesis with a steel wire that would keep the condyles in place. Steinhauser ${ }^{21}$ made the same recommendation several months later in an article devoted to the benefits derived from supra-hyoid myotomy in cases of retruded mandibles accompanied by anterior open bite.

Using a steel wire for osteosynthesis does not, however, guarantee stability as much as the inter-maxillary splints that remain indispensible in early surgical treatment for retruded mandibles where orthodontic treatment can later extrude anterior teeth that have been mobile to varying degrees. What is indispensible is surgeon's periodic stabilization of the fragments of mandible by tightening the steel wires.

Midway through the decade of the 1980s the introduction of screws or plates inserted into cortical bone made osteosynthesis truly rigid and reliable transformed orthognathic surgery. They assured the permanence of the joint between fragments of bone and made application of a bite block between upper and lower molar teeth unnecessary. Surgeons were able to position condyles accurately and 
reliably in their fossas with the assurance that the bone fragments would not shift. This did not totally eliminate relapse, however, especially in cases where mandibular advancement had been considerable ${ }^{11,25}$.

\section{- Bone grafts}

When surgeons have made large movement of fragments of maxillary or mandibular bone, they may have to

\section{INDICATIONS}

If surgery is usually indicated for patients with hyperdivergence, at least in severe cases, it is essential that its primary objective be restoration of function for nasal breathing, for providing adequate pharyngeal and oral cavity space, and for permitting lip closure. In this connection the lapidary phrase of Paul Tessier, the father of modern craniofacial surgery, about the maxillary bones in hyperdivergent patients comes happily to mind, "Never too large, never too far in advance." This nicely sums up the general directions in which surgeons will move basal bone. And it is, as always, in the clinical examination and the cephalometric analysis that surgeons will find the precise causes of hyperdivergence and morphological anomalies as well as the best methods with which to repair them.

The age at which the intervention should be undertaken depends on

\section{STABILITY OF RESULTS (fig. 6, 7, 8)}

After making an extensive review of the literature and evaluating their own considerable personal experience, fill the residual space with osseous grafts in order to assure continuity between the parts and thereby encourage their consolidation. Depending on the situation, surgeons may select an autologous site for the donor bone such as the vomer, the menton area, or the cranial vault. The iliac crest is also available as a grafting source but it usually provokes post-operative pain while the cranium is a site that is especially comfortable for patients.

the functional disorders revealed during the clinic exam whose persistence would threaten to aggravate the malformations. Nasal obstructions and mandibular hypoplasia tend to interfere with maxillary growth. Surgeons can operate on deviated nasal septa before puberty. If the patient is too old for functional orthodontic appliances to operate effectively, surgeons can plan osteotomies after eruption of the second molars and intervene even earlier to lengthen the ascending rami of the mandible with an inverse $L$ osteotomy accompanied by molar bite blocks. In the case of severe mandibular hypoplasia surgeons can employ progressive distraction osteogenics $^{23}$. On the other hand, it is best to wait for the end of the growth period when the mandibular deficiency is moderate ${ }^{16}$.

Proffit, Phillips and Turvey published a 1996 article on the stability of orthognathic surgical results in relation 


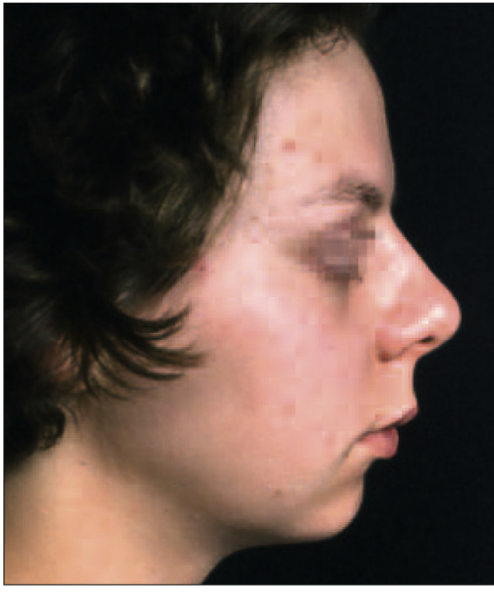

a
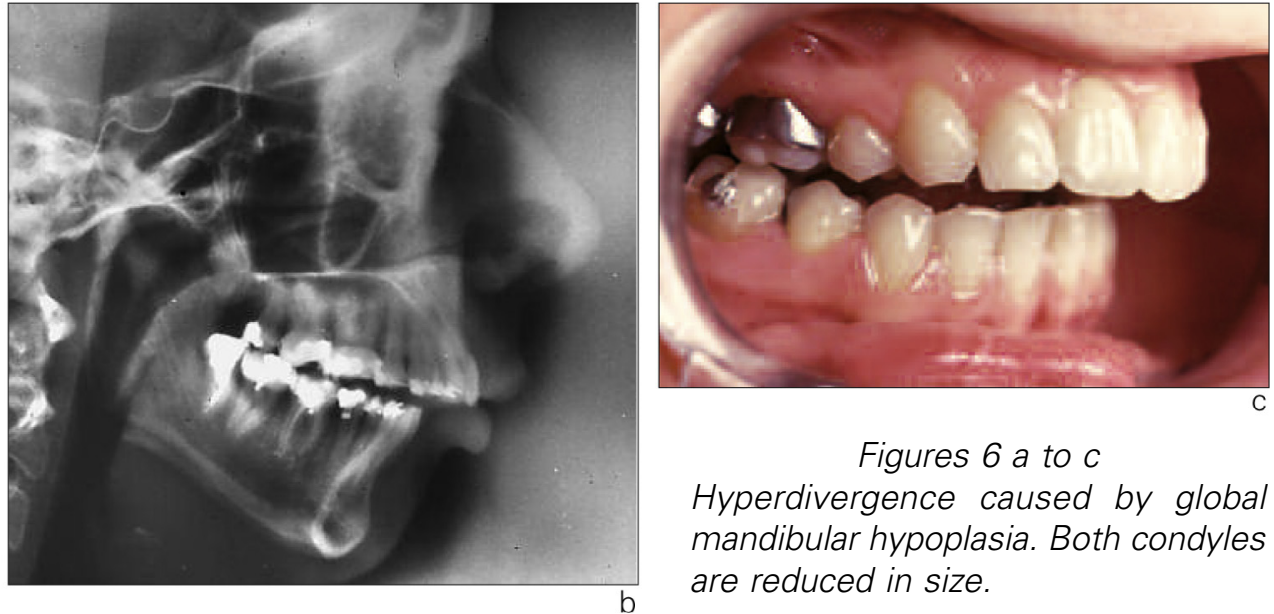

Figures 6 a to $c$

Hyperdivergence caused by global mandibular hypoplasia. Both condyles are reduced in size.
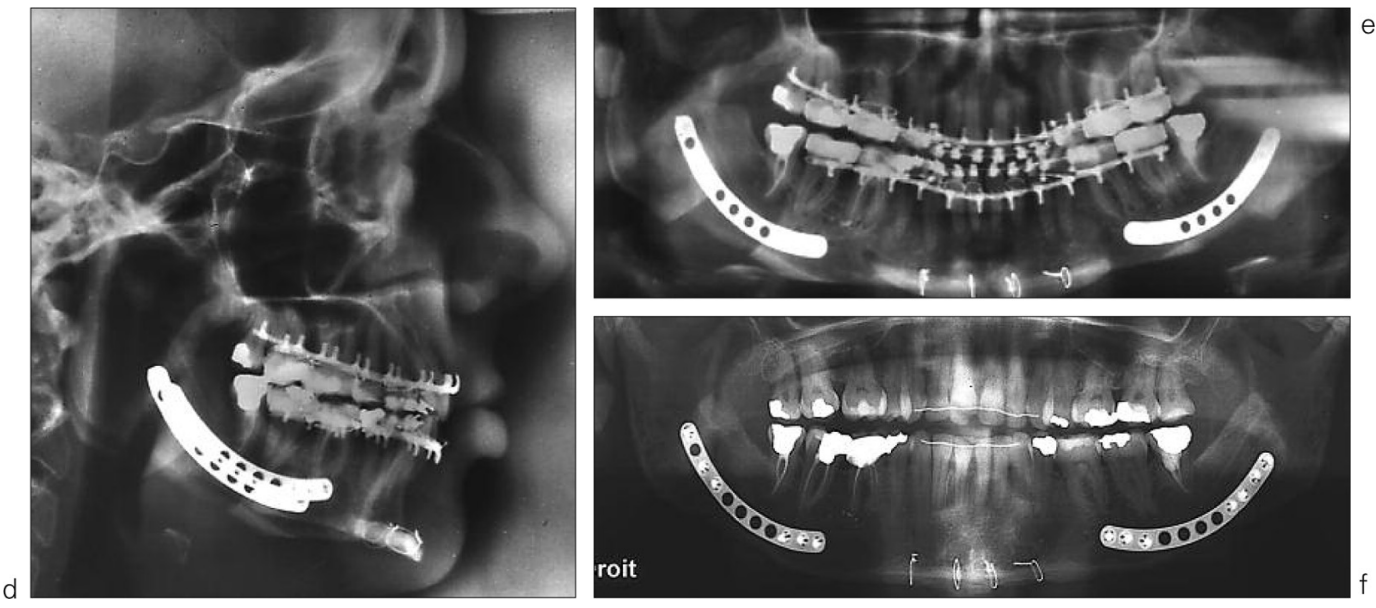

Figures $6 d$ to $f$

After having mandibular advancement and genioplasty in March 1990 (d-e), patient received lingual orthodontic

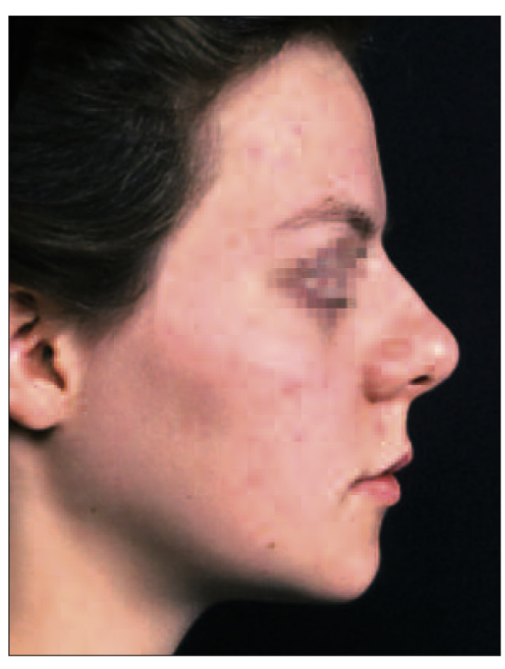

g treatment by D. Fillion, who fitted her with buccal arches during the operation so that she could wear elastic bands. No bite blocks were used operatively. Check-up radiographs were taken at the end of treatment. (f)

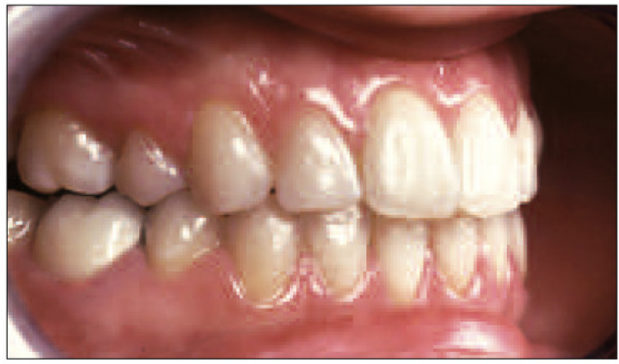

$\mathrm{h}$

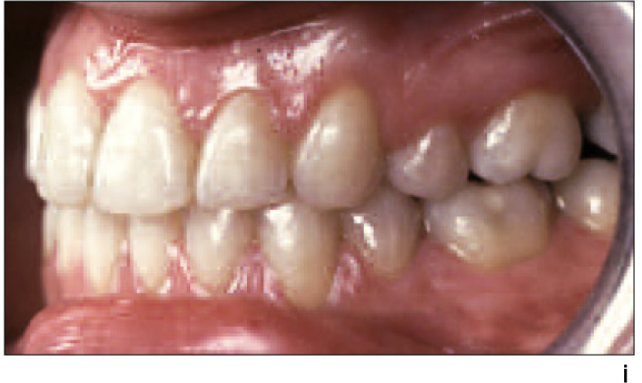

Figures $6 \mathrm{~g}$ to $i$

Clinical view at the end of treatment. When patient was seen again for a checkup in January 2002, the results were still perfectly stable. 


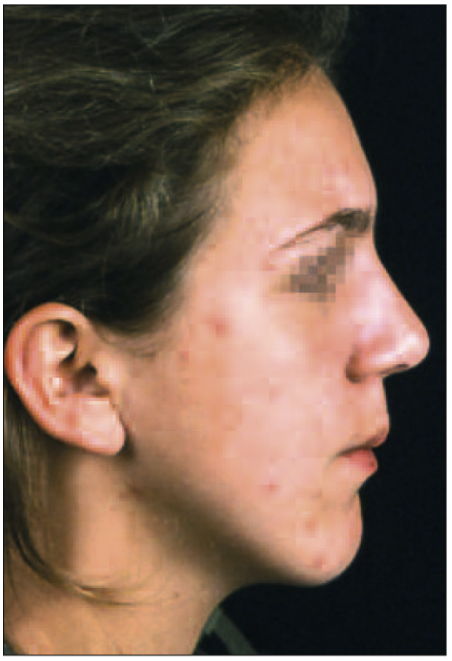

a

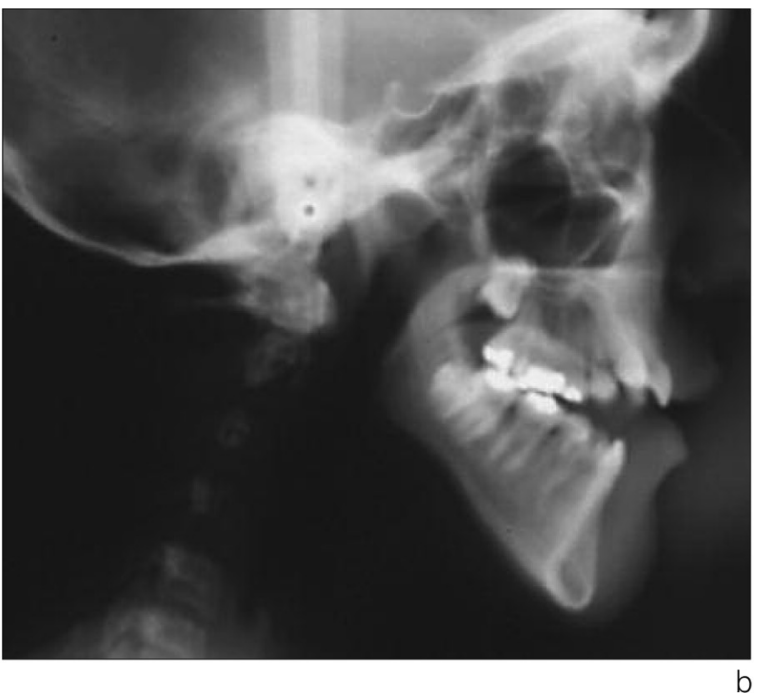

Figures 7 a to $c$

Hyperdivergence caused by excess vertical growth of the maxilla. Both upper and lower arches were seriously retruded and a severe arch length discrepancy, insufficient space for correct alignment of teeth, existed in both upper and lower jaws.

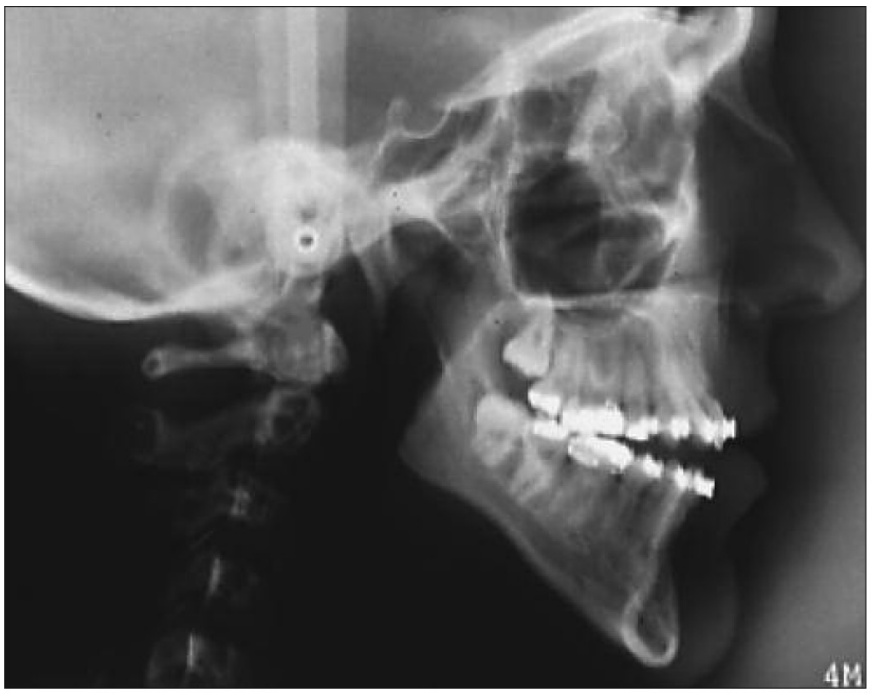

d $\quad$ Figures $7 d$ to $f$

After surgical-orthodontic palate splitting and progressive widening of the space between the two maxillary segments with a Hyrax appliance. Orthodontic treatment accompanied by extraction of four premolars was begun.
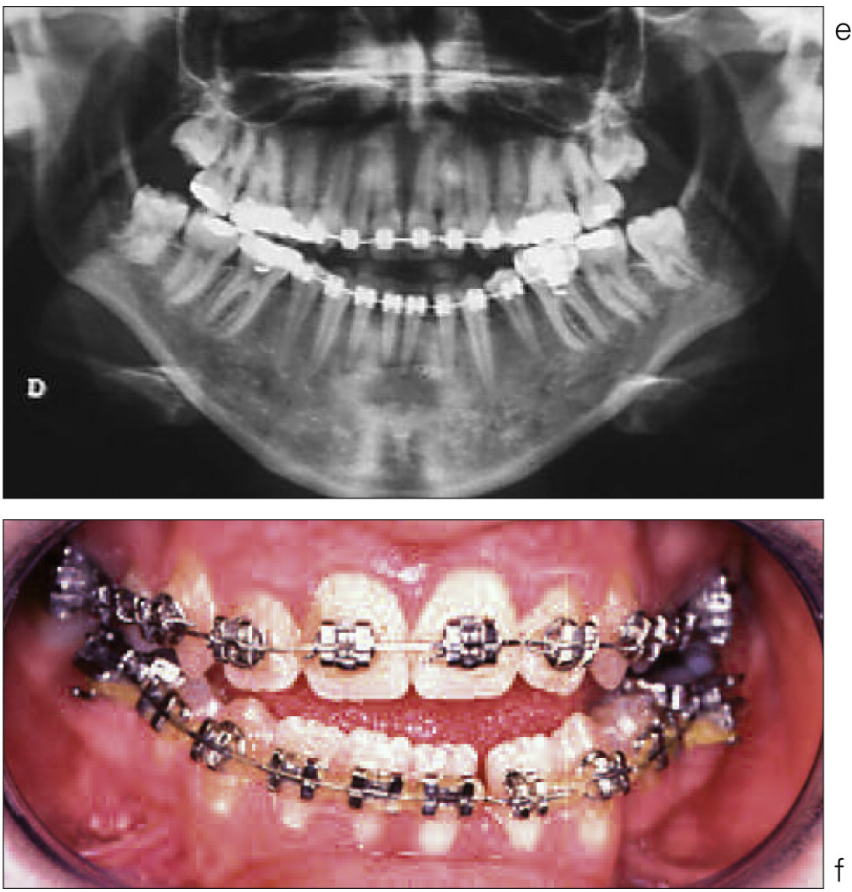


\begin{tabular}{|c|c|c|}
\hline Sagittal Skeletal Relation & $\begin{array}{l}\text { 29/11/97 } \\
\text { Pre treatment }\end{array}$ & $\begin{array}{l}02 / 2001 \\
\text { Before surgery }\end{array}$ \\
\hline $\begin{array}{l}\text { Maxillary Position } \\
\text { S-N-A }\end{array}$ & $71,0^{\circ}$ & $71,0^{\circ}$ \\
\hline $\begin{array}{l}\text { Mandibular Position } \\
\text { S-N-Pog }\end{array}$ & $71,0^{\circ}$ & $73,0^{\circ}$ \\
\hline $\begin{array}{l}\text { Sagittal Jaw Relation } \\
\text { A-N-Pog }\end{array}$ & $0,0^{\circ}$ & $-2,0^{\circ}$ \\
\hline \multicolumn{3}{|l|}{ Sagittal Skeletal Relation } \\
\hline $\begin{array}{l}\text { Maxillary Inclination } \\
\text { S-N / ANS-PNS }\end{array}$ & $10,0^{\circ}$ & $10,0^{\circ}$ \\
\hline $\begin{array}{l}\text { Mandibular Inclination } \\
\text { S-N/Go-Gn }\end{array}$ & $54,0^{\circ}$ & $51,0^{\circ}$ \\
\hline $\begin{array}{l}\text { Vertical Jaw Relation } \\
\text { ANS-PNS / Go-Gn }\end{array}$ & $44,0^{\circ}$ & $41,0^{\circ}$ \\
\hline \multicolumn{3}{|l|}{ Dento-Basal Relation } \\
\hline $\begin{array}{l}\text { Maxillary Incisor Inclination } \\
1 \text { - ANS-PNS }\end{array}$ & $112,0^{\circ}$ & $110,0^{\circ}$ \\
\hline $\begin{array}{l}\text { Mandibular Incisor Inclination } \\
1-\text { Go-Gn }\end{array}$ & $62,0^{\circ}$ & $78,0^{\circ}$ \\
\hline $\begin{array}{l}\text { Mandibular Incisor Compensation } \\
1 \text { - A-Pg (mm) }\end{array}$ & $-1,0 \mathrm{~mm}$ & $+1,0 \mathrm{~mm}$ \\
\hline \multicolumn{3}{|l|}{ Dento Relation } \\
\hline Overjet (mm) & $+7,00 \mathrm{~mm}$ & $3,0 \mathrm{~mm}$ \\
\hline Overbite (mm) & $-9,0 \mathrm{~mm}$ & $-4,0 \mathrm{~mm}$ \\
\hline Interincisal Angle 1/1 & $139,0^{\circ}$ & $131,0^{\circ}$ \\
\hline
\end{tabular}
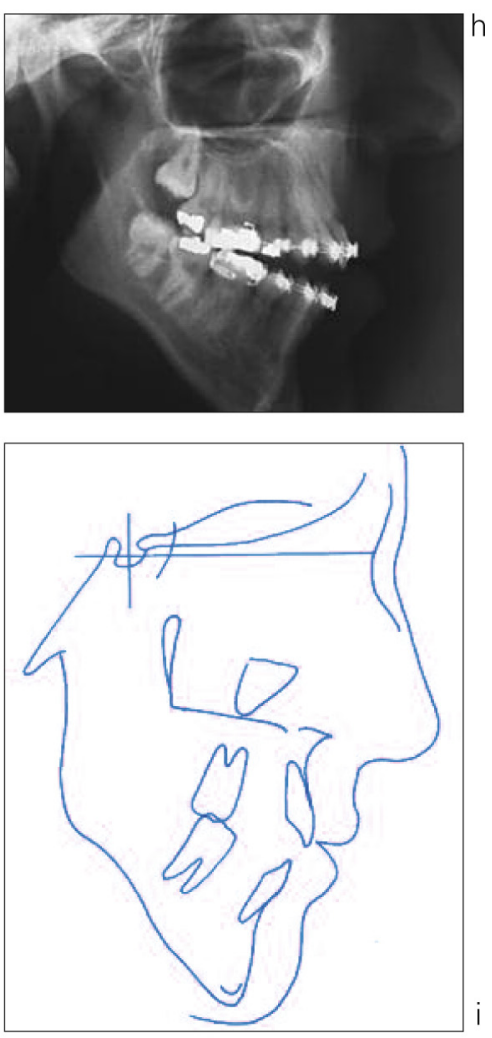

g
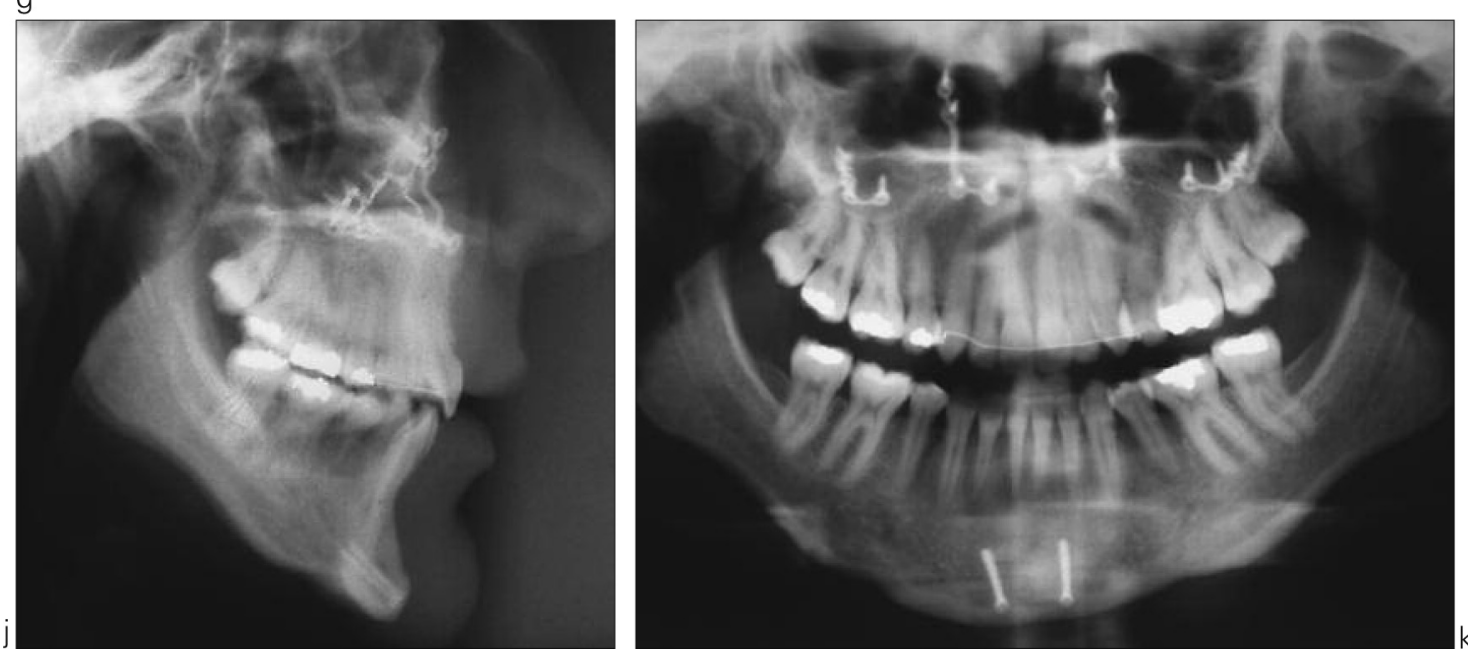

Figures $7 j$ to $k$ After closure of the open bite by Le Fort I osteotomy with ingression of the posterior maxillary teeth and genioplasty. 

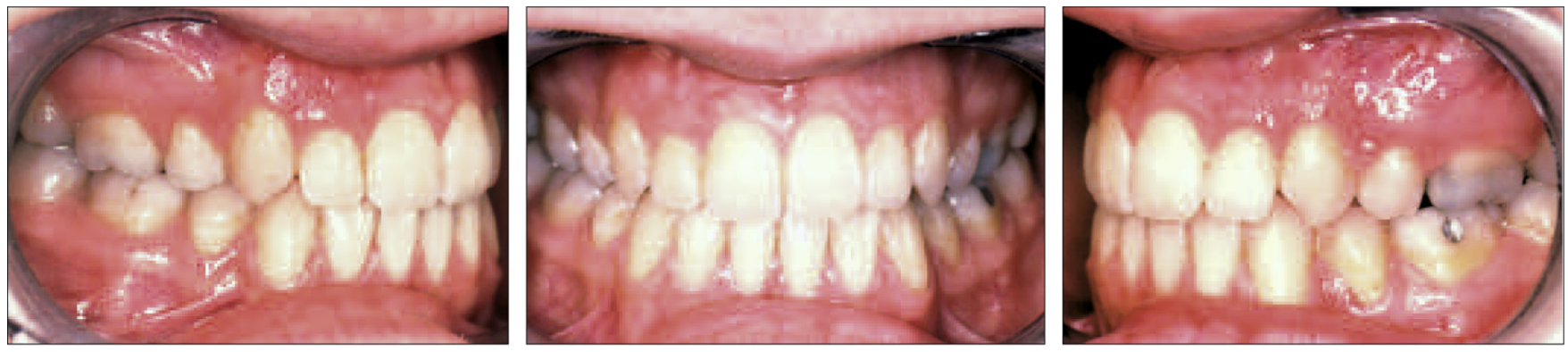

$\mathrm{m}$

Figures 7 I to $n$

Occlusion at the end of treatment.

\begin{tabular}{|c|c|c|}
\hline Sagittal Skeletal Relation & $\begin{array}{l}\text { 29/11/97 } \\
\text { Pre treatment }\end{array}$ & Post Treatment \\
\hline $\begin{array}{l}\text { Maxillary Position } \\
\text { S-N-A }\end{array}$ & $71,0^{\circ}$ & $76,0^{\circ}$ \\
\hline $\begin{array}{l}\text { Mandibular Position } \\
\text { S-N-Pog }\end{array}$ & $71,0^{\circ}$ & $76,0^{\circ}$ \\
\hline $\begin{array}{l}\text { Sagittal Jaw Relation } \\
\text { A-N-Pog }\end{array}$ & $0,0^{\circ}$ & $0,0^{\circ}$ \\
\hline \multicolumn{3}{|l|}{ Sagittal Skeletal Relation } \\
\hline $\begin{array}{l}\text { Maxillary Inclination } \\
\text { S-N / ANS-PNS }\end{array}$ & $10,0^{\circ}$ & $14,0^{\circ}$ \\
\hline $\begin{array}{l}\text { Mandibular Inclination } \\
\text { S-N / Go-Gn }\end{array}$ & $54,0^{\circ}$ & $42,0^{\circ}$ \\
\hline $\begin{array}{l}\text { Vertical Jaw Relation } \\
\text { ANS-PNS / Go-Gn }\end{array}$ & $44,0^{\circ}$ & $28,0^{\circ}$ \\
\hline \multicolumn{3}{|l|}{ Dento-Basal Relation } \\
\hline $\begin{array}{l}\text { Maxillary Incisor Inclination } \\
1 \text { - ANS-PNS }\end{array}$ & $112,0^{\circ}$ & $110,0^{\circ}$ \\
\hline $\begin{array}{l}\text { Mandibular Incisor Inclination } \\
1-\text { Go-Gn }\end{array}$ & $62,0^{\circ}$ & $87,0^{\circ}$ \\
\hline $\begin{array}{l}\text { Mandibular Incisor Compensation } \\
1-\mathrm{A}-\mathrm{Pg}(\mathrm{mm})\end{array}$ & $-1,0 \mathrm{~mm}$ & $+1,5 \mathrm{~mm}$ \\
\hline \multicolumn{3}{|l|}{ Dento Relation } \\
\hline Overjet (mm) & $+7,00 \mathrm{~mm}$ & $+2,5 \mathrm{~mm}$ \\
\hline Overbite (mm) & $-9,0 \mathrm{~mm}$ & $+2 \mathrm{~mm}$ \\
\hline Interincisal Angle 1/1 & $139,0^{\circ}$ & $134,0^{\circ}$ \\
\hline
\end{tabular}
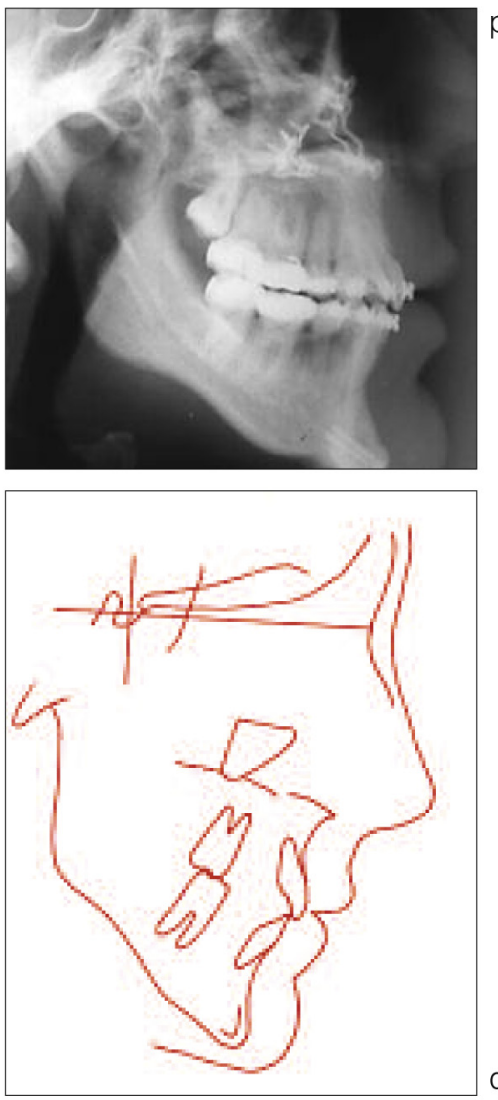

p

Figures 7 o to $q$ Cephalometric analysis at the end of treatment. 


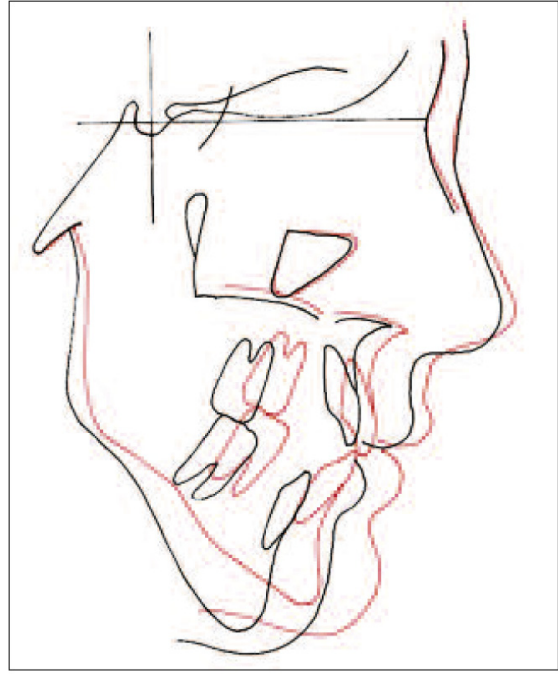

Figures $7 r$

Superimposition of before and after cephalometric tracings.

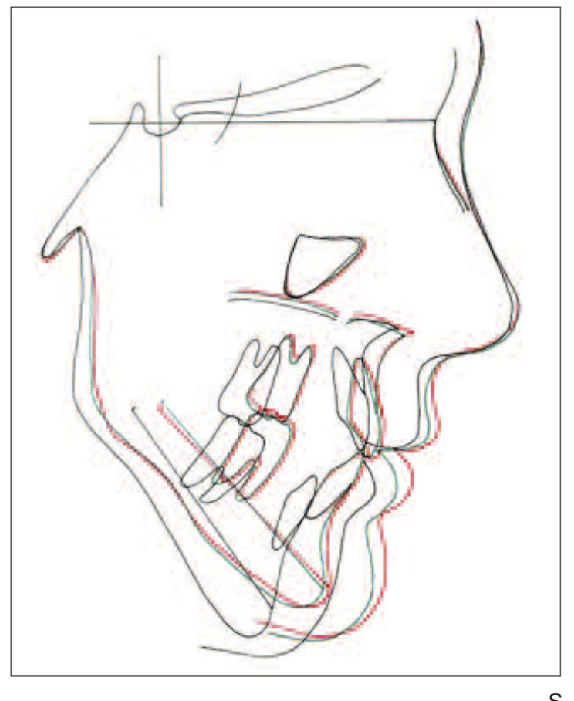

Figures $7 \mathrm{~s}$

A superimposition of cephalometric tracings two years after the end of treatment shows the very slight relapse that occurred despite the patient's having received myofunctional tongue therapy.
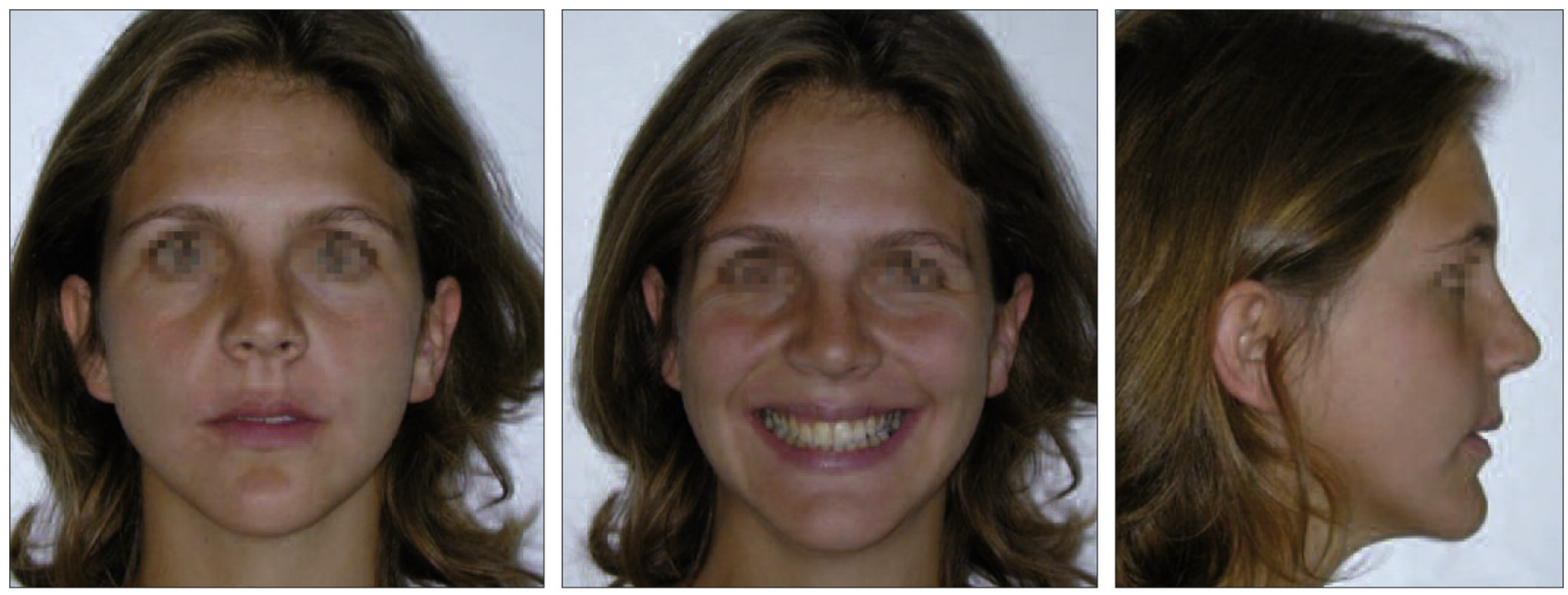

$\mathrm{t}$

u
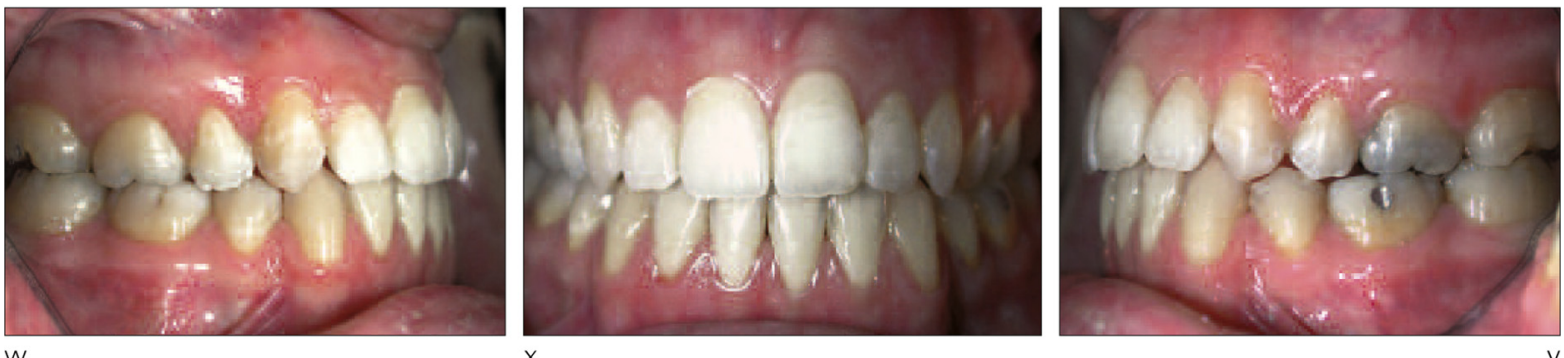

Figures $7 t$ to $y$

Intraoral views two years after the close of treatment. 


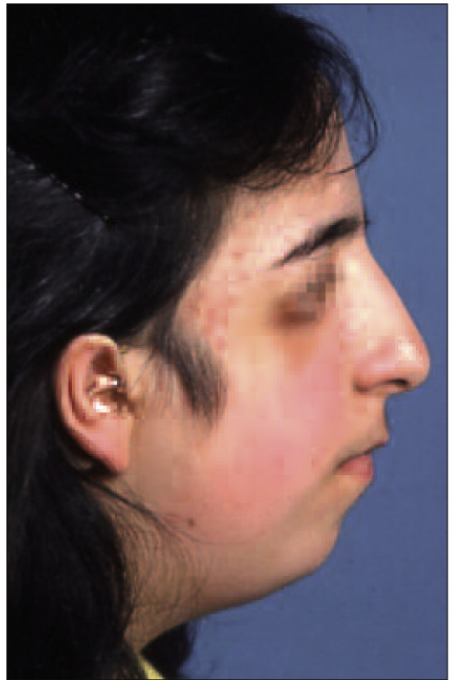

a

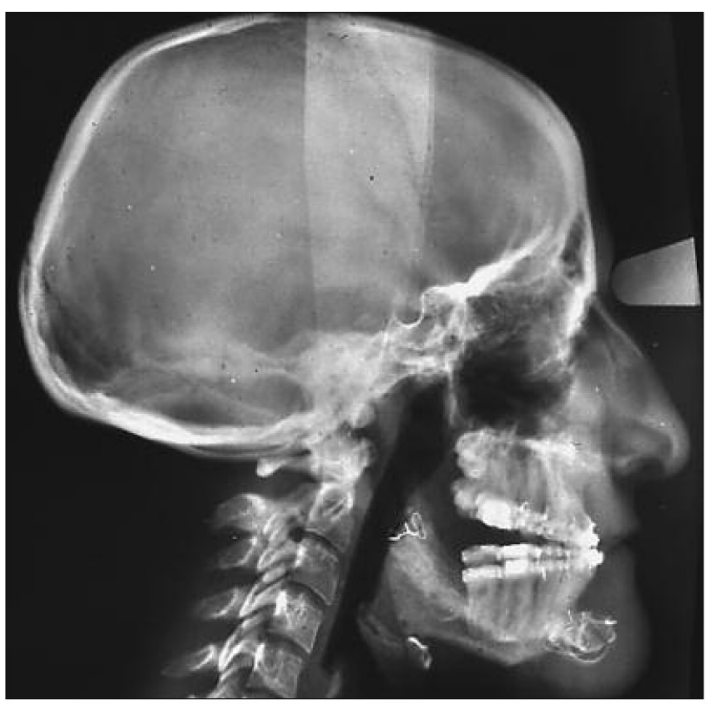

C

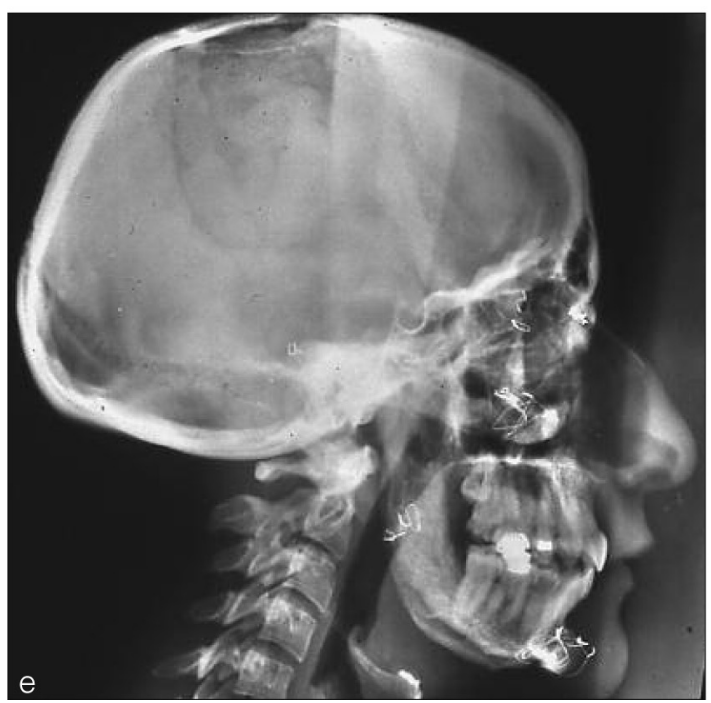

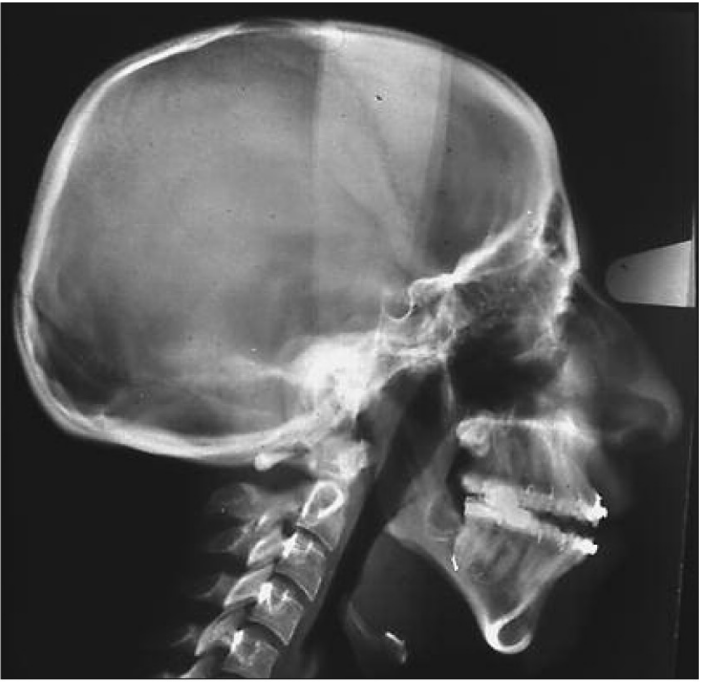

b
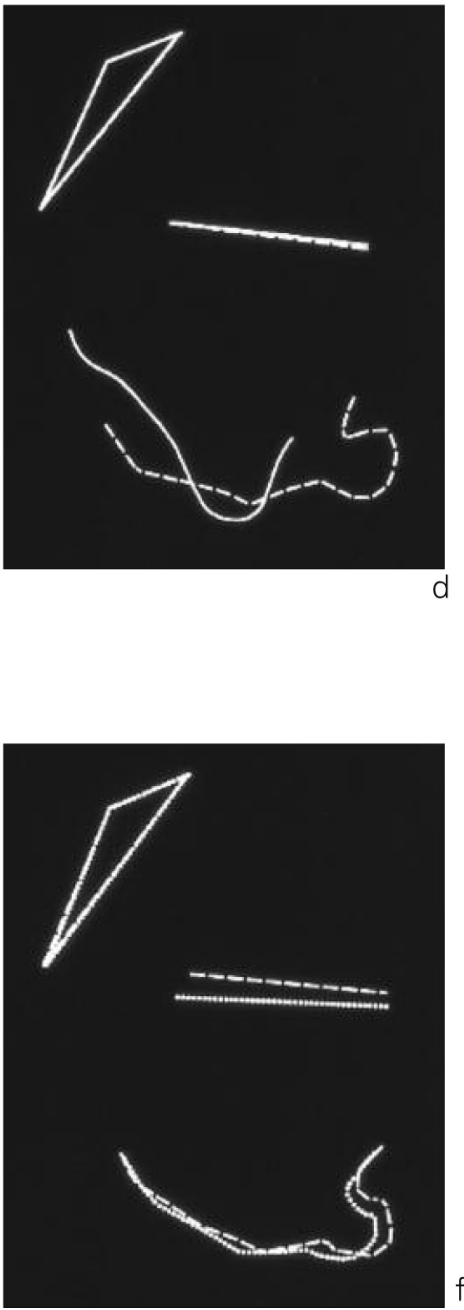

Figures $8 a$ and $b$

A high mandibular angle was the cause of this patient's hyperdivergence. The curvature of the lower border of her mandible is a characteristic symptom of the Franceschetti syndrome that she suffered from.

\section{Figures $8 c$ and $d$}

After having lengthened the ascending rami with inverse $L$ osteotomies in July 1982, the surgeon used a bone graft from the iliac to stabilize a genioplasty. Georges Rozencweig used the fixed triangle BasionSella to the sphenoid-ethmoid intersection, which was not affected by the fronto-nasal surgery, to superimpose his tracings.

Figure $8 e$ and $f$

Tracings before and 6 months after massive II facial surgery in July 1983. The resorption of the genioplasty fragments was already noticeable before the tracings were made. 


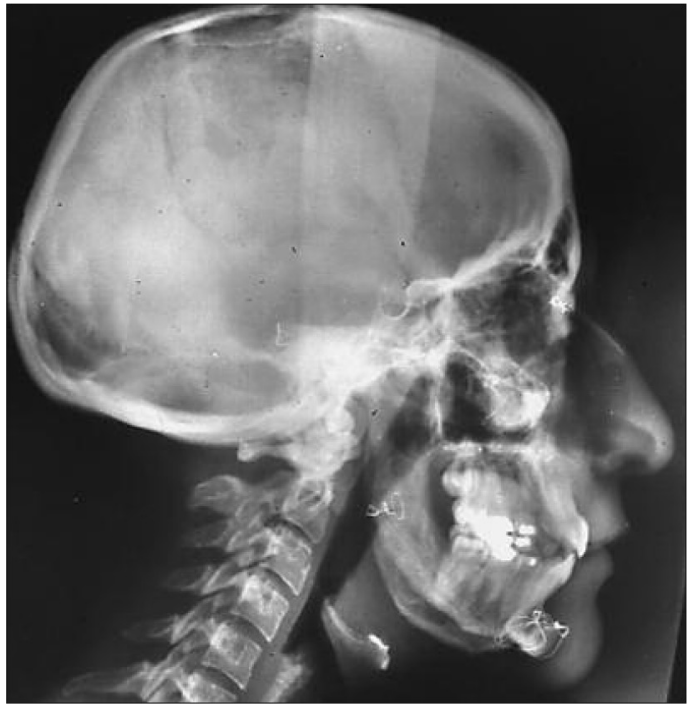

g

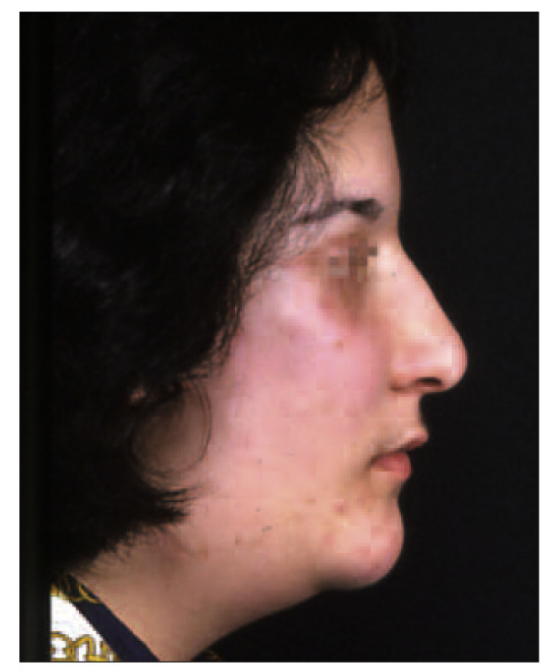

i

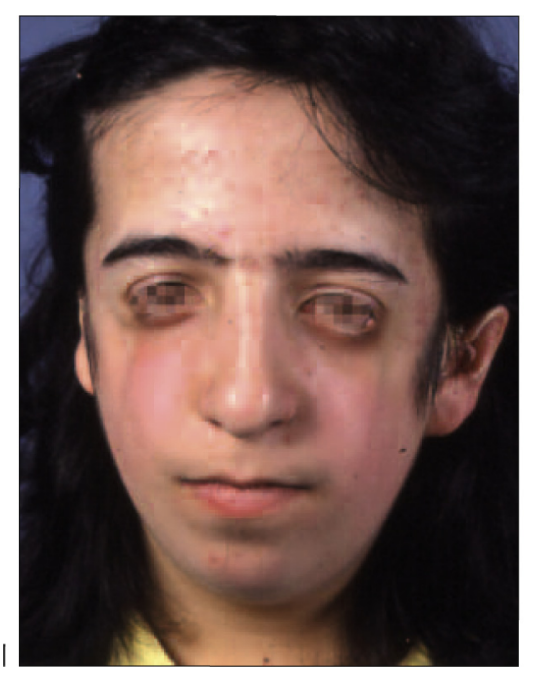

Figures $8 \mathrm{~g}$ and $h$

Superimposed tracings of January 1984 and March 1986 show the stability of both maxillary and mandibular results.

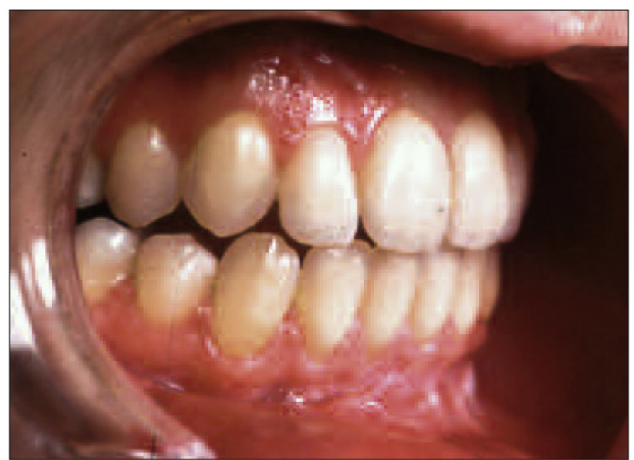

Figures 8 / to $k$

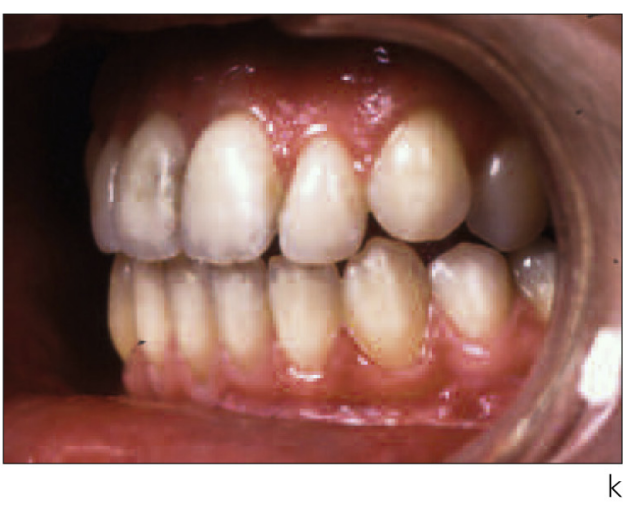

k

Clinical views after Henri Labarrere had completed orthodontic treatment.

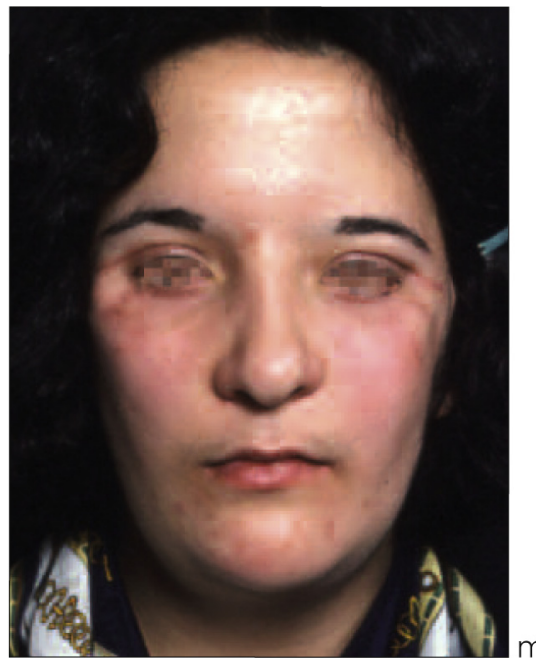

Figures $8 /$ and $m$

Before and after osteotomy facial views. The patient had also had two operations on her eyelids, her orbits, and on the malar bones with iliac bone grafts. 
to the extent of the displacements accomplished $^{17}$. We can now contemplate their conclusions after a fifteenyear period, especially with regard to maxillary expansion and mandibular advancement.

- Maxillary intrusion is very stable no matter what fixation, steel wire blocking or screwed mini-plates, is used.

- Maxillary advancement is stable in $80 \%$ of the cases regardless of what fixation is employed.

- Maxillary expansion is the least stable procedure. Fifty per-cent of expansion width gained in an osteotomy is lost after the operation has been performed and the osseous fragments fixated in an individually pre-formed splint made to the desired specifications. But Proffit, Phillips and Turvey make no mention in their article of the use of progressive palate splitting ex-pansion after the osteotomy.

To obtain this information we must refer to two more recent articles $^{2,12}$ that give details on long term, up to 6 years, results of this widely used technique known as Surgically Assisted Rapid Palatal Expansion (SARPE) :

- surgically assisted expansion provides more stable results and causes fewer periodontal problems than orthopedic expansion alone;

- osteotomies offer the benefit of being complete, also spreading the pterygo-maxillary complex. Only the very narrow posterior portion of the external nasal walls is preserved in order to maintain the vertical position of the two hemimaxillae;
- the enlargement of skeletal structures is stable but a secondary result of the buccal inclination of maxillary segments is a lingual tipping of posterior teeth that causes a loss of about $30 \%$ of the expansion gained. Accordingly for every 7 to $8 \mathrm{~mm}$ of expansion they create, it is advisable for practitioners to over-correct by $2 \mathrm{~mm}$.

- The more mandibular advancement is associated with posterior rotation of the body, the more stable it becomes. On the other hand, anterior, or counter- rotations, clockwise, rotations run the risk of relapse, or of causing a maxillary intrusion as happened in the preceding case. The risk of relapse increases as the extent of advancement increases. We have already described in detail all the means that must be taken to assure a stable result no matter how severe the mandibular deficiency may be (cf. "Prevention of relapse"). After Epker published an exhaustive list of recommendations in a 1978 article that covered every stabilizing technique except rigid osteosynthesis that had not yet been incorporated into orthognathic surgery, other writers, in many articles 3,18 , $19,20,27$, have presented very stable operative treatment results, with a minimum of relapse, on many dozens of patients. Results that were just as stable can be found in a study of 47 female patients, treated by the same surgeon, in similar operating times, for complete tempero-mandibular joint prostheses with maxillo-mandibular counter-clockwise rotation and mandibular advancement ${ }^{4}$. 


\section{CONCLUSION}

Surgeons can obtain stable results in the correction of maxillo-mandibular malformations accompanied by facial hyperdivergence provided they deal exhaustively with the functional components of the complex, above all the muscular ones. After having made a detailed diagnosis and discerned the indications with the aid of a Delaire analysis, they should pay particular attention, depending on the case, to these aspects of the problem :

- assuring that sufficient space will be available for the tongue and for facilitating nasal respiration by advancing and enlarging the maxilla,

- increasing pharyngeal space by liberating the maxilla through lengthening of the ascending rami and advancement and counter-clockwise rotation of the mandible,

- totally removing muscular and ligamentary attachments at the angles and the symphasis of the mandible so that the mandibular body can be properly aligned without any constraints afterward being exerted on it,

- restoring balance to the labio-menton muscles, assuring ready lip closure at rest, and, if necessary, performing a genioplasty.

Practical steps practitioners can take to assure stability include :

- postponing surgical intervention until patients become adults unless esthetic blemishes are so severe that earlier intervention is advisable,

- eliminating in pre-operative orthodontic preparation all dental compensations, especially in the transverse sense, because they are almost certain to relapse if corrected surgically,

- using progressive rapid palatal expansion, after complete osteotomies to make treatment orthopedic, that is skeletal, not exclusively dental, with over-correction of maxillary or mandibular deficiencies,

- positionning the bone segments in correct, passive position before fixating them with plates or screws,

- over-correcting, to varying extents depending on the amount of the movement and always within the limits of detailed orthodontic finishing,

- using a one or two-stage operative procedure depending upon the age of the patient and the extent of the movement required.

- filling all inter-osseous gaps, caused by operative displacement of segments, with autogenous bone grafts, not osseous substitutes as has been suggested in some publications,

- and finally, the orthodontist's conducting a long-term follow-up with whatever adjustments are required and whatever help may be needed by a myo-functional therapist, to maintain the patient's occlusion in excellent balance. 


\section{REFERENCES}

1. Björk A. Bilateral hypoplasia of mandibular condyle. In Kraus B.S, and Riedel R.A. (ed.) : Vistas in Orthodontics. Philadelphia: Lea and Febiger, 1962.

2. Chamberland S, Proffit WR. Closer look at the stability of surgically assisted rapid palatal expansion. J Oral Maxillofac Surg 2008 Sep;66(9):1895-1900.

3. Chemello PD, Wolford LM, Bushang PH. Occlusal plane alteration in orthognathic surgery. Part II : Long-term stability of results. Am J Orthod Dentofacial Orthop 1994 Oct; 106(4):434-440.

4. Coleta KE, Wolford LM, Goncalves JR, Dos Santos Pinto A, Pinto LP, Cassano DS. Maxillomandibular counter-clockwise rotation and mandibular advancement with TMJ Concepts total joint prostheses. Part I Skeletal and dental stability. Int J Oral Maxillofac Surg 2009;38:126-138.

5. Dal Pont G. Retromalar osteotomy for the correction of prognathism. J Oral Surg 1961 (jan);19:42.

6. Delaire J. L'analyse architecturale et structurale cranio-faciale (de profil). Principes théoriques. Quelques exemples d'emploi en chirurgie maxillo-faciale. Rev Stomatol 1978; 79(1):1-33.

7. Delaire J, Schendel SA, Tulasne JF. An architectural and structural craniofacial analysis : A new lateral cephalometric analysis. Oral Surg Oral Med Oral Pathol. 1981 Sep;52(3): 226-238.

8. Delaire J, Tulasne JF. Les déséquilibres labio-mentonniers par excès vertical antérieur de l'étage inférieur de la face. Apport de la géniectomie segmentaire horizontale. Orth Fr 1979; 50:353.

9. Epker BN, Wolford LM, Fish LC. Mandibular deficiency syndrome. II Surgical considerations for mandibular advancement Oral Surg 1978;March:349-363.

10. Ferri J, Girod A, Serghini A, Lemiere E. Allongement de la branche montante sans abord externe dans les insuffisances verticales postérieures de la mandibule. Rev Stomatol Chir Maxillofac 2006;107:38-40.

11. Kierl MJ, Nanda RS, Currier GF. A 3-year evaluation of skeletal stability of mandibular advancement with rigid fixation. J. Oral Maxillofac Surg 1990;48:587.

12. Magnusson A, Bjerklin K, Nilsson P, Marcusson A. Surgically assisted rapid maxillary expansion : long. term stability Eur J Orthod 2009;31:142-149.

13. McNeill RW, West RA. Severe mandibular retrognathism : Orthodontic versus surgical orthodontic treatment. Am J Orthod 1977;72:176-182.

14. Poulton DR, Ware WH. Surgical orthodontic treatment of severe mandibular retrusion. Am J Orthod 1971;59:244-265.

15. Poulton DR, Ware WH. Surgical orthodontic treatment of severe mandibular retrusion (Part II). Am J Orthod 1973;63:237-255.

16. Proffit WR, Turvey TA, Phillips C. Orthognathic surgery: A hierarchy of stability. Int J Adult Orthod Orthognath Surg 1996;11(3):191-204.

17. Proffit WR, Phillips C, Turvey TW. Longterm stability of adolescent versus adult surgery for treatment of mandibular deficiency Int J Oral Maxillofac Surg 2010 Apr;39(4):327-332.

18. Reyneke JP, Bryant RS, Suuronen R. Becker P.J. Postoperative skeletal stability following clockwise and counter-clockwise rotation of the maxillomandibular complex compared to conventional orthognathic treatment. $\mathrm{Br} \mathrm{J}$ Oral Maxillofac Surg 2007;45:56-64.

19. Ricard D, Ferri J. Modification of the sagittal split osteotomy of the mandibular ramus: Mobilizing vertical osteotomy of the internal ramus segment. J Oral Maxillofac Surg 2009;67:1691-1699.

20. Rosen HM.Occlusal Plane Rotation: Aesthetic enhancement in mandibular micrognathia. Plat Rec Surg 1993 Jun;91(7):1231-11239. 
21. Steinhauser EW. Advancement of the mandible by sagittal ramus split and suprahyoid myotomy. J Oral Surg 1973 Jul;31(7):516-521.

22. Trauner $R$, Obwegeser $H$. Surgical correction of mandibular prognathism with considerations of genioplasty. II. Operating methods for microgenia and distocclusion. Oral Surg 1957;10:677-689.

23. Tulasne JF. Hypoplasies mandibulaires. Intérêt du traitement chez l'enfant. Orthod Fr $1981 ; 52: 553$.

24. Tulasne JF. Mandibular Micrognathia. Analysis and treatment. Clin Plast Surg. 1982 Oct; 9(4):519-530.

25. VanSickels JE, Larsen AJ, Thrash WJ. Relapse after rigid fixation of mandibular advancement. J. Oral Maxillofac Surg 1986;44:698.

26. Wolford LM, Walker G, Schendel S, Fish LC, Epker BN. Mandibular deficiency syndrome. I. Clinical delineation and therapeutic significance. Oral Surg Oral Med Oral Pathol 1978 Mar;45(3):329-48.

27. Wolford LM, Chemello PD, Hilliard D. Occlusal plane alteration in orthognathic surgery. Part I: Effects on function and esthetics. Am J Orthod Dentofac Orthop 1994;106:30416. 